\title{
Mulheres viajantes no mundo romano (séc. IV-V d.C.)
}

\author{
Women traveling in the Roman world (4th-5th century AD)
}

\author{
Silvia M. A. Siqueira*
}

\begin{abstract}
Resumo: Este artigo versa sobre viagens de mulheres que viveram entre os séculos IV e V. O estudo analisa a questão do deslocamento para a Terra Santa por meio do Itinerarium Burdigalensis e procura compreender o discurso sobre quatro mulheres que viajaram para a Palestina. Helena, mãe do imperador Constantino; Egéria, a peregrina que redigiu o seu diário de viagem; e duas matronas romanas, Paula e Melânia, que não apenas decidiram viajar como também atuaram de modo ímpar, vivendo em novos lugares, construindo e interferindo na paisagem com a edificação de mosteiros, auxílio aos peregrinos, etc. Seu objetivo é compreender como a memória dessas viajantes contribui para alimentar um imaginário coletivo, porque a viagem proporciona uma identidade ao território e também para a própria viajante que faz do seu percurso um elemento fundamental da sua vida. Nesse sentido, a viagem ultrapassa a mera metáfora para a ampliação de novos horizontes; ela é uma prática da alteridade.
\end{abstract}

\begin{abstract}
This article is about the women's travels who lived between the 4 th and 5th century AD. The study analyzes the issue of displacement to the Holy Land through the Itinerarium Burdigalensis and then seeks to understand the discourse about four women who traveled to Palestine. Helena, mother of Emperor Constantine, Egeria the pilgrim who wrote his travel diary and two Roman matrons Paula and Melanie who not only decided to travel, but also acted in a unique way, living in new places, building and interfering in the landscape with the building of monasteries, assistance to pilgrims, etc. Finally, understanding how the memory of these travelers contributes to feed a collective imagination, because the trip provides an identity to the territory and, also for the traveler herself, who makes her journey a fundamental element of her life, in this sense, the trip is much more than a metaphor for expanding new horizons, it is a practice of alterity.
\end{abstract}

\section{Palavras-chave:}

Mulheres romanas. Viagens. Espacialidades. Memória.

\section{Keywords:}

Roman Women.

Travels.

Spatialities.

Memory.

\footnotetext{
* Professora de História Antiga da Universidade Estadual do Ceará (Uece). Doutora em História pela Universidade Estadual Paulista Júlio de Mesquita Filho. Realizou pós-doutorado na Universitá degli Studi Roma Tre (2013). Seus estudos versam sobre História das Mulheres no cristianismo antigo.
} 


\section{Introdução}

[...] quando rejeitamos a história única, quando percebemos que nunca existe uma história única sobre lugar nenhum, reavemos uma espécie de paraíso

(ADICIHIE, 2019, p. 33).

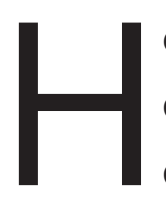

oje é possível encontrar vários veículos de informação sobre viagens dedicadas exclusivamente a mulheres, sítios na internet, aplicativos, guias de viagens, livros e simples roteiros com o objetivo comum de informar e facilitar o deslocamento feminino, indicando a segurança dos locais e todas as possibilidades de usufruto da excursão. E nos tempos pretéritos? O senso comum diz que, no passado, não era possível uma mulher fazer sua mala e partir, visto que o suposto lugar dela seria o recanto do seu lar, junto aos seus. Ora, sabemos que não foi bem assim, como se houvesse apenas uma história, pois "[...] as mulheres sempre viajaram, fosse a sós, acompanhando os pais, maridos, em peregrinação, missão, pesquisa ou simplesmente pelo simples prazer de viajar" (SERRANO, 2014, p. 10). Assim, tomando esta premissa, aqui faremos uma reflexão sobre a viagem de mulheres no século IV e no início do século $V_{1}{ }^{1}$ justamente para abandonar estereótipos femininos construídos parcialmente e que trouxeram apenas um olhar para a história, o qual, em última instância, determinou um imaginário coletivo em torno das mulheres viajantes.

Selecionamos, para este artigo, as seguintes mulheres: Helena, mãe do imperador Constantino (ㄴ248-329); as matronas romanas Paula (347-404) e Melânia Maior (350-410); e Egéria, a autora de um livro de viagens provavelmente composto no final do século IV ou início do século V. Com exceção da última viajante, que possivelmente escreveu o relato da sua viagem, o deslocamento das outras foi registrado por seus biógrafos, sendo, portanto, relatos de segunda mão, o que não invalida a narrativa, mas é necessário analisar o seu contexto discursivo, considerando os interesses dos responsáveis pela memória dessas mulheres.

Ao modo de Hartog (2004), o presente texto se ocupa de narrativas que informam viagens e movimentos, entendidos para além da ação de deslocamento, isto é, também como um ato que permite sair de si, do seu mundo em direção ao outro, seja outro lugar, seja outro mundo. Muito mais do que ver o lugar é a experiência de sair da imaginação e experimentar concretamente aquele ambiente que ilustra a alteridade.

\footnotetext{
${ }^{1}$ Sobre mulheres que viajaram nesse recorte temporal, cf. Albina citada por Gerôncio na Vita Sanctae Melaniae (35; 41); Eustáquia citada por vários autores, especialmente Jerônimo em Epistolário $(108,4)$ e Paládio em História Lausiaca (41); Fabíola é mencionada por Jerônimo em Epistolário (64 ,8; 77, 7-9); Melânia Minor biografada por Gerôncio em Vita Sanctae Melaniae; Marana e Cyra mencionadas por Teodoreto de Cirro na Historia religiosa (29, 7).
} 
Este autor emprega o termo "homens-fronteira" para analisar a experiência da viagem como um ver que é também um saber em diferentes tempos e espaços. Aqui, não temos "mulheres-fronteiras", e o tema está muito mais para a mobilidade própria de "mulheres de passagem" que transitam não apenas de um lugar para o outro, mas de uma vida para um outro modo de vivenciar e ver o mundo. Elas navegam, cavalgam ou caminham para conhecer não apenas os lugares santos como também para encontrar e ver homens e mulheres que superaram os seus limites, alimentados pela força de sua fé. Elas fazem intervenções e realizam benemerência, reagem ao contexto e mobilizam o seu lugar de partida, nem sempre voltam para o lugar de partida. Elas se movimentam no espaço da alteridade. Cada lugar visitado está pautado por uma narrativa. Então, é também um espaço cultural e da experiência. Provando o prazer da mobilidade e da descoberta de outro mundo, para as "mulheres de passagem" o caminho percorrido, em especial o ponto de partida e a trajetória, é mais relevante do que o destino final da viagem. Por fim, o itinerário é o elemento discursivo responsável pelo registro da memória. Ele é também a linha condutora da narração das passageiras. O itinerário não apenas atravessa, mas também organiza os lugares por onde elas passam criando imaginários. Como afirma Certeau (2009, p. 182), qualquer que seja o relato, ele é sempre "um relato de viagem".

Uma especificidade das viagens aqui consideradas é que comumente elas são definidas como peregrinações, no sentido de prática devocional. É a devoção que impulsiona a visita aos lugares considerados sagrados, seja com objetivo votivo ou penitencial. Entretanto, na Antiguidade essa prática tem características específicas e diferentes da peregrinação cristã (SANTI, 2005). Nem Roma nem a Grécia tinham um termo específico para nomear a prática de peregrinar com objetivo religioso. Peregrinus, em latim, indica uma realidade jurídica e não uma ação religiosa, ou seja, a pessoa que está fora dos limites da sua comunidade. Quando o termo recebe o advérbio peregre (distante), passa a indicar quem está longe de sua comunidade, sem a conotação religiosa. O sentido de atitude, com objetivo de cumprir uma tarefa religiosa, é parte do ambiente monoteísta (SANTI, 2005, p. 34) e não raro liga-se ao aspecto devocional da religiosidade não oficial. É no quarto século que esta prática se intensifica entre os cristãos e passa a figurar no cenário religioso. A palavra recebe um valor semântico para indicar a viagem cuja intenção é visitar um lugar onde viveu algum santo. As viagens aqui narradas registram visitas à Terra Santa, o local onde Jesus cumpriu a sua missão redentora da humanidade, mas antes dele ali também estão os profetas e os inúmeros personagens bíblicos.

Um primeiro elemento de promoção da mobilidade das viagens é a rede de serviços capazes de favorecer os deslocamentos. Os antigos romanos construíram estradas para conectar as inúmeras províncias com Roma para não apenas minimizar as distâncias, mas 
também possibilitar a mobilidade do exército e o uso para fins políticos, administrativos e comerciais. Como vemos, os motivos para viajar eram variados, sendo o mais comum o trabalho para os correios. Conhecido como cursus publicus (ou dromos, em grego), este serviço era um sistema de deslocamento por terra que, desde Augusto, assegurava o transporte de encomendas e documentos oficiais. O método capaz de viabilizar a rapidez e eficiência baseava-se na mudança de estações (mutationes) e alojamentos (mansiones) que pontilhavam estradas romanas a cada dezesseis quilômetros, aproximadamente um dia de viagem. As estações e os alojamentos recebiam exclusivamente viajantes oficiais que necessariamente deveriam apresentar a documentação adequada.

As vias eram abertas a todas as pessoas, não apenas aos funcionários dos correios. Soldados e mercadores se movimentavam de um lado para outro. Os veículos utilizados eram variados, muitas vezes simples viajantes se lançavam nos caminhos e partiam em longas viagens a pé. $O$ trânsito de pedestres nas estradas romanas era intenso. Aqueles que possuíam algum meio de transporte animal tinham mais conforto e atingiam com maior rapidez o seu destino. A infraestrutura dos serviços era garantida para os viajantes oficiais que tinham a autorização no uso das estações, que forneciam aos animais comida fresca, água, cuidados veterinários, e também estalagens que ofereciam comida, bebida, além de alojamento aos viajantes. Para os viajantes não oficiais, eram oferecidos serviços pagos porque, ao redor das mutationes e das mansiones, orbitavam inúmeras categorias de prestadores de serviços (SESSA, 2018, p. 154).

Além das estradas com infraestrutura, é possível encontrar no itinerarium - ou, no plural, itineraria - uma lista de aldeias, vilas, cidades e estações de correios do Império Romano, com as distâncias entre eles. Eles foram concebidos conforme os conceitos básicos formulados por cartógrafos gregos, como Agripa e Ptolomeu, e eram frequentemente usados por viajantes particulares e oficiais. Em resumo, uma espécie de guia das estradas do mundo romano. Encontramos dois tipos de itinerários: o itinerário escrito (itineraria scripta) e o itinerário ilustrado com figuras (itineraria picta). ${ }^{2}$

O Itinerarium a Burdigala Jerusalem usque et ab Heraclea per Aulonam et per urbem Romam Mediolanum usque é o registro mais antigo de um itinerário cristão. ${ }^{3}$ Foi escrito aproximadamente entre os anos de 333-334 por uma pessoa não identificada que registrou a sua viagem de Burdigala, a moderna Bordéus, até Jerusalém com o objetivo de visitar o Santo Sepulcro. O Itinerarium Burdigalense segue o modelo Antonini. Ambos

\footnotetext{
2 Os itineraria mais conhecidos são: Tábua Peutingeriana (Tabula Peutingeriana), Itinerário Antonino (Antonini Itinerarium), Peregrinação de Etéria (Peregrinatio Aetheriae/Itinerarium Egeriae) e o Itinerário Burdigalense, Itinerarium Burdigalense ou Itinerarium Hierosolymitanus, ambos objeto do presente estudo.

${ }^{3} \mathrm{O}$ documento recebe várias denominações: Itinerarium Burdigalense e Itinerarium Hierosolymitanum.
} 
foram redigidos segundo o gênero dos escritos de viagem greco-romano e indicam a mesma via, contemplam a paisagem entre Bordéus até Milão e, daí, até Jerusalém. Contudo, o Burdigalense apresenta algumas variações, ${ }^{4}$ pois não apenas indica a lista das cidades, as principais vias e suas respectivas distâncias, mas também apresenta os detalhes de numerosas variantes no trajeto. Está subdividido em duas seções, sendo uma para viagens por terra e outra para deslocamentos por mar, com as principais rotas marítimas do Mediterrâneo. Uma diferença significativa é que este proporciona informações sobre a viagem de uma pessoa cristã. $O$ trajeto está delineado com fins de visita aos lugares santos. Nele, encontramos não apenas informações dos caminhos, mas também dos locais sagrados de parada. Essa característica do itinerário, com descrições entrelaçadas, faz dele singular nos círculos literários. A parte intermediária do relato também tem afinidades com as técnicas de mapeamento da época, mapas contemporâneos de levantamento de terras enfatizam as rotas e confins, bem como alguns distritos e marcos notáveis (LEYERLE, 1996, p. 124).

O viajante de Bordéus descreveu todas as etapas do percurso, distinguiu o tipo das estações nas categorias principais (mutationes e mansiones) e usou o termo civitas para designar cidades. Ele registrou castelos ou fortes (castellum ou omis comme Ad Pirum) e aldeias (vicus), produzindo assim uma descrição cuidadosa que triplica a indicação de lugares quando comparado a outros itinerários da Antiguidade. Além disso, parece que ele viajou oficialmente e tinha a documentação para isso, que poderia ser o evictio ou tractoriae, ou seja, autorização para usar todos os serviços do cursus publicus.

Enfim, muito mais do que uma simples descrição, o traçado do Itinerarium Burdigalense oferece informações de como viajar no Império Romano, registra não apenas a rota e a topografia do caminho, mas igualmente situa a organização das estradas e descreve a espacialidade - em especial, a disposição de Jerusalém no tempo de Constantino. No âmbito do conhecimento, ele possui uma linguagem específica que informa o significado dos lugares e ilustra as primeiras formas de peregrinação cristã. Ao fim, é um guia do peregrino que informa sobre as liturgias cristãs celebradas em determinados locais no decorrer do trajeto em Jerusalém (ELSNER, 2000, p. 182). A escrita parece ser bastante pessoal. Há equívoco, por exemplo, quando o peregrino confunde a

\footnotetext{
${ }^{4} \mathrm{O}$ itinerário contém o seguinte trajeto: de Bordéus até Toulouse, dessa localidade vai para Arles e segue até Milão. Dirige-se para Aquileia, daí para Sírmio, Sérdica; na sequência, Constantinopla. A viagem segue até Nicomédia e dessa cidade para Ancara. Seguindo para Tarso, dirige-se para Antioquia, depois vai para Tiro. Daí, finalmente segue para Cesareia, já na Palestina. Depois, Jerusalém. Em seguida, continua a viagem e visita Jericó, Belém, Beitsahour, Terebinto, Hebron. O narrador retorna para Jerusalém, daí para Cesareia, muda o percurso para Heracleia, depois Aulona, daí para Cápua Vetere. Segue para Roma, dirige-se a Rimini até chegar a Milão, quando termina o itinerário percorrido. Assim, ele conclui: "Fit omnis summa ab urbe Roma Mediolanum usque milia CCCCXVI, mutationes XLII, mansiones XXIIII Total entre la ville de Rome et Mediolanum (Milan), 416 milles, 44 changements, 24 haltes" (IT. B., 617, 6-8).
} 
Ascensão com a Transfiguração (Itinerarium Burdigalense, 595, 6; 596, 1) e, curiosamente, Nazaré não comparece no texto, tampouco o Mar da Galileia, possivelmente porque ele não visitou esses lugares. $O$ documento traça ainda um mapa mental da representação espacial da viagem efetuada por ele. Basta considerar que a indicação dos lugares sagrados pode ser o ponto teológico codificado neste "mapa" para reforçar a facticidade dos eventos da história da salvação (LEYERLE, 1996, p. 126).

Outro aspecto a ser considerado a respeito do Itinerarium Burdigalense, segundo Elsner (2000), é expressão das múltiplas transformações em diferentes aspectos da cultura romana no período tardio. Segundo ele, a composição está de acordo com as formas tradicionais do gênero relativo a registro de viagens greco-romano. Contudo, o autor acrescenta elementos para inseri-lo no universo cristão, não apenas no aspecto do deslocamento, mas também como uma forma de viagem que passará a se denominar peregrinação, e o império como um conceito territorial definido por lugares privilegiados particulares e suas mitologias únicas.

Nesse sentido, o espaço imperial está representado no Itinerarium por meio da escrita que registra a experiência de viagem e do terreno por onde o peregrino passou. $O$ seu texto proporciona ao leitor a oportunidade de experimentar a paisagem de um território que impulsiona o crescente imaginário religioso cristão. Trata-se, por fim, de um texto que elabora uma nova imagem do Império Romano: Jerusalém é o ponto de parada mais significativo da narrativa em uma estrutura recém-cristianizada, e a Palestina é apresentada com meios fundamentalmente diferentes dos outros do resto do mundo romano.

\section{Helena: o enigma da viagem}

Helena (Flavia Iulia Helena), ${ }^{5}$ mãe do imperador Constantino, protagoniza a prática de viagem com escopo religioso, em especial para conhecer e experimentar o mundo do Cristo. A ela também se atribui o feito de ter encontrado a verdadeira cruz de Jesus Cristo. $O$ encontro dessa relíquia ocorreu em meio a um projeto ambicioso de reconstrução da cidade de Jerusalém, destruída nos séculos I e II após revoltas e rebeliões. A partir da viagem e da visita cumprida em inúmeros locais considerados santos, monumentos cristãos são edificados para lembrar aos peregrinos - e peregrinas - dos vários locais da paixão e ressurreição de Cristo.

Sobre Helena, sabe-se pouco. Há várias lacunas a seu respeito. Sabe-se um pouco mais no tocante à parte final de sua vida, tendo falecida como Augusta, imperatriz e

\footnotetext{
${ }^{5}$ Em estudo anterior, foi possível refletir sobre a imperatriz Helena. Cf. Siqueira (2017, p. 314-333).
} 
peregrina. Eusébio de Cesareia não hesitou ao afirmar que ela foi santificada pelas extraordinárias atitudes do filho: "foi ele que a fez devota, de modo que parecia ter sido ela instruída pelo próprio Salvador em pessoa, e foi o próprio Constantino que a honrou com a dignidade imperial Augusta" (Eusébio de Cesarea, Vita Costantini, III, XLVII, 2). Rufino a define como uma "mulher de incomparável fé, pela sinceridade religiosa e por singular magnificência, da qual Constantino era filho" (Rufino, Historia Ecclesiastica, I, 7). Esse autor modela a imagem de uma mulher imbuída dos mais nobres sentimentos que influenciou a conversão do filho imperador.

Aqui, vamos nos deter sobre a viagem de Helena para a Terra Santa. Infelizmente, o episódio não está registrado em primeira pessoa. Ela não deixou registro próprio sobre a sua experiência, nem mesmo sobre sua vida. Temos, porém, imagens narrativas elaboradas por outros autores. Possivelmente, a mais importante, que traz informações contemporâneas à existência dela, é aquela proporcionada por Eusébio de Cesareia, o "biógrafo oficial de Constantino" (Eus., Vit. Const., III, XLI-XLVII). Por meio dele, sabe-se que Helena iniciou sua viagem já com idade avançada, próxima dos 80 anos (Eus., Vit. Const., III, XLIII, 5). Não obstante, "[...] a mulher anciã com entusiasmo juvenil, na sua extraordinária sabedoria, chega a conhecer aquela terra admirável e a visitar as províncias e as populações orientais com desvelo régio" (Eus., Vit. Const., III, XLII, 1). Na abordagem desse autor, a viagem tem motivos pessoais e também uma natureza oficial: a visita seria uma solicitude imperial (basilikè prométheia) com a população de todas as províncias orientais. Então, são dois aspectos, o espacial e o humano, que motivam a viagem. $O$ emprego da palavra promètheia indica a providência própria dos imperadores em favor dos povos do Império (CONSOLINO, 1994, p. 197) e pode apontar para a questão de que a ida para aquela localidade não tem uma natureza única e exclusivamente religiosa. Mas o problema continua: por que, apesar da idade avançada, Helena se aventuraria numa viagem em favor do filho e dos netos, herdeiros legítimos de Constantino? Da documentação é possível depreender que a soberana morreu em 329, pouco tempo depois de voltar da Terra Santa. Portanto, muito possivelmente a missão no exterior ocorreu entre os anos de 327 e 328.

Para alguns estudiosos, a motivação da jornada teria alguma relação com o episódio da condenação do primogênito de Constantino, Crispo, cuja morte ocorreu no ano de 326. Não há notícias seguras sobre as razões da morte do rapaz. O que se sabe é que a pena capital foi ordenada pelo próprio pai. ${ }^{6} \mathrm{O}$ jovem César teve uma carreira brilhante, sua

\footnotetext{
${ }^{6}$ Alguns autores antigos registraram informações sobre esse trágico episódio da família imperial. Cf. Eutropius, Breviarium (10, 6, 3); Hieronymus, De viris illustribus, 80; Zósimo, Historia Nova (2, 29, 2).
} 
efígie aparece em moedas, retratos, esculturas, mosaicos. Curiosamente, no mesmo ano, a própria esposa de Constantino, Fausta, também foi condenada à morte. Seguramente, as duas condenações estão relacionadas, mas há várias versões sobre as causas. Alguns dizem que Fausta e Crispo, que tinham praticamente a mesma idade, se apaixonaram e foram descobertos e condenados. Há outra versão de que Fausta conspirou contra o jovem, acusando-o de seduzi-la para que ele fosse retirado da linha sucessória. Posteriormente, Constantino teria descoberto a mentira e a trama em relação ao trono, condenando a própria esposa à morte. Alguns autores sustentam que Helena tinha profunda afeição pelo neto e, inconformada com a tragédia familiar, teria decidido pela viagem para superar a tristeza. Enfim, o ano de 326 não apenas marca esta tragédia familiar, mas também delimita a intensificação da política religiosa em favor do cristianismo. ${ }^{7}$

A narrativa descreve Helena com energia própria da juventude e o entusiasmo ímpar dos viajantes. Ela, na ânsia de ver pessoalmente a terra onde Jesus viveu, seguiu o conselho: "Entremos no lugar em que ele mora, prostremo-nos diante do seu pedestal" (Salmo, 131b). Além de apreciar em pessoa a paisagem, verdadeiro palco da existência de uma divindade na terra, Helena quis encontrar a gente dali e assisti-la com zelo próprio de sua condição régia (Eus., Vit. Const., III, 42, 2). Então, a soberana não apenas visitou a gruta da natividade, mas também o monte da ascensão, consagrou ambos os sítios com decoração e ricos ornamentos. "De fato o Deus que está conosco, por nossa causa aceitou fazer-se homem, e o lugar onde nasceu da carne em hebraico, se chama Belém" (Eus., Vit. Const., III, 43, 1). Depois, pelos sinuosos caminhos partiu de Belém para Jerusalém, sentiu o ar seco e a poeira do percurso daquele espaço, palco das últimas adversidades do Cristo. Também aí não apenas viu a paisagem, mas interferiu e mandou construir vários monumentos:

E ainda, a mãe do imperador exaltou a memória da ascensão ao céu do Salvador do universo no Monte das Oliveiras, fez construir ali soberbos edifícios erigindo, quase acima do monte, na costa mais alta, o edifício sagrado de uma igreja e, sempre no mesmo lugar, edificou um santuário de oração em honra do Salvador que descansou naquele lugar. Conforme atesta um conto verdadeiro, ali, naquela mesma gruta, o Salvador do universo iniciou os seus discípulos nos inefáveis mistérios (Eus., Vit. Const., III, 43, 3)

Em cada celebração de Helena, na sequência, é mencionado algum ato de Constantino. O foco narrativo das ações piedosas da soberana está intimamente

\footnotetext{
${ }^{7}$ O silêncio de Eusébio sobre os trágicos episódios relacionados à morte de Crispo e Fausta podem ajudar a reforçar as inúmeras evidências do comprometimento do discurso desse autor com a construção de uma imagem quase que imaculada de Constantino. Ao falar dos pais, ele traz muitas informações sobre Constâncio Cloro. Quando se refere à mãe, Helena, discorre sobre atitudes relacionadas à religiosidade de Constantino. Assim, o excursus do capítulo informa as providências do soberano para dignificar a gruta da natividade, também o local onde ocorreu a ascensão, como o motivo para homenagear sua mãe. Cf. CONSOLINO (2013).
} 
entrelaçado com a exaltação das atitudes do filho: "A imperatriz Helena, piedosa mãe de um piedoso imperador, fundou assim, em honra do seu Deus Salvador, estes dois magníficos e esplêndidos santuários dignos da eterna memória das duas grutas santas" (Eus., Vit. Const., III, 43,4). As iniciativas de Helena proporcionam elementos para posteriores demonstrações de religiosidade de Constantino, que, além de apoiar a mãe, faz com que se acrescentem às obras iniciadas por ela mais suntuosidade e beleza.

Considerando os diferentes aspectos da narrativa de Eusébio sobre a viagem de Helena, é possível perceber que ele não aponta diretamente uma intervenção política específica nessa viagem. Todo o capítulo indica que a soberana fez uma peregrinação religiosa e aproveitou a oportunidade para cumprir ações próprias da munificência real. Nessa época, como mencionado acima, peregrinar ainda não é uma atitude comum, a ação de peregrinação gradativamente será uma moda. Nesse caso, é perceptível que não foi uma excursão simplesmente para ver com os próprios olhos, mas possivelmente também para benefício político. Na sequência, o zelo imperial comparece na narrativa, evidenciando que a excursão teve um caráter oficial. Nessa época, Helena já recebera o título de Augusta Imperatrix: "visitou todo o Oriente na magnificência da sua nobreza imperial e beneficiou com inúmeros donativos" (Eus., Vit. Const., III, 44). Vários segmentos foram beneficiados por essa visita oficial, tanto as populações das diferentes cidades quanto os indivíduos que procuraram a soberana; até mesmo o exército recebeu sua generosidade. Os mais pobres, desvalidos e indefesos não foram esquecidos: para alguns, ofereceu dinheiro, outros ela presenteou com roupas para cobrir o corpo. Também libertou oprimidos pelo sofrimento do cárcere e das minas, franqueou vários que eram vítimas de abusos. Outros foram anistiados do exílio (Eus., Vit. Const., III, 44).

Os estudos de Drijvers $(1992 ; 2011)$ demonstram que Eusébio errou ao relatar a viagem como uma peregrinação religiosa. Segundo ele, Helena viajou para apaziguar a sua insatisfação em relação à política de cristianização viabilizada pelo seu filho. Drijvers (2011) pauta sua análise na comparação das doações aos desamparados, feitas por Helena, com aquelas efetuadas por Constantino. Ele entende que este último está preocupado com a conversão, enquanto a soberana está preocupada em suavizar a resistência à nova religião. Por sua vez, Lenski (2004) interpreta a razão para a viagem de Helena como um ato intimamente relacionado à morte de Crispo. Segundo ele, a Augusta partiu logo após o trágico episódio como uma forma de protesto contra a atitude do filho. E Constantino, transcorrido algum tempo, passaria a apoiar as iniciativas da mãe no decorrer da viagem, quando percebeu que as ações de benemerência e construção tiveram sucesso, em especial a de sacralizar mais uma vez os lugares santos. 
Sobre o objetivo da viagem de Helena, Consolino (2013) entende que a missão dela ultrapassa as fronteiras religiosas e tem vários objetivos. Por um lado, o desejo de agradar a Igreja via benemerência e construção de monumentos, por outro, a própria atitude imperial que abraça diferentes estratos sociais, desde doações para o exército até a anistia para presos e injustiçados. O patrocínio para as cidades pode indicar uma tentativa de consolidação da dinastia constantiniana.

Ao minimizar os inúmeros danos provocados pela guerra civil até a vitória de Constantino, Helena seria a executora de um programa político bem elaborado para melhorar a imagem do filho. Todas as atitudes fazem parte dos encargos oficiais e têm o consentimento do imperador, que coloca parte do seu tesouro pessoal à disposição da mãe. Então, a excursão para a Terra Santa suavizou as lembranças da violência recente que possibilitou a chegada de Constantino ao poder. Também oferece uma imagem positiva da família imperial consolidada por meio da política de propaganda do período. Considerando as questões acima apresentadas, é possível supor que Helena viajou por diferentes motivos, seja como peregrina, seja como Augusta, seja ainda como apenas uma mulher cuja vida foi permeada por sucessivas disputas pelo poder. Sobre ela ainda recairá a responsabilidade por encontrar a verdadeira cruz do Cristo.

Difícil precisar os motivos pessoais para a viagem de Helena. Mesmo com tantas interpretações a partir das evidências, o motivo permanece uma incógnita. O certo é que a visita dela trouxe várias consequências posteriores, em particular, o aumento de viagens feitas por mulheres. Nos rastros de Helena, várias pessoas - especialmente mulheres - reinventaram o propósito e destino das viagens. A ida para a Terra Santa também marcou a abertura de uma contínua (re)encenação durante todo o ano da vida e paixão de Cristo, cumprida pelo bispo e pelo povo em Jerusalém. Usando os locais (re)descobertos e (re)construídos por Helena, peregrinos de todo o mundo romano puderam dar vida à palavra divina das escrituras como a base da vida cotidiana naquele espaço físico (LENSKI, 2004, p. 122).

É ainda sobre Helena que Rufino de Aquileia ${ }^{8}$ (Hist. Eccl., I, 7-8) narra a busca pela verdadeira cruz. Em um estilo bem diferente de Eusébio de Cesareia, este autor registra como a soberana, por meio de uma revelação divina, encontra não uma, mas três cruzes. Para saber qual seria a verdadeira, recebeu a ajuda do monge Macário, bispo de Jerusalém. Assim, por meio da intervenção divina, chegam à verdadeira cruz. A soberana também é descrita por sua humildade ao servir pessoalmente as virgens consagradas. $O$

\footnotetext{
${ }^{8}$ Rufino deu continuidade ao trabalho de Eusébio de Cesareia, intitulado História Eclesiástica. A narrativa eusebiana termina no Concílio de Niceia (325). Rufino prolongou a narrativa, tratando particularmente da Igreja até a morte de Teodósio, no ano de 395.
} 
que há de interessante nesse caso é que a narrativa sobre Helena parece mais próxima de lendas quando ela é inserida junto aos elementos simbólicos do monacato, um monge, Macário, e as virgens consagradas, além da relíquia sagrada da cruz e os pregos da crucificação. Quando Rufino escreveu sobre ela, a Terra Santa já era um local consolidado de peregrinação cristã, e Helena é retratada como uma peregrina piedosa que se encontra com os homens santos e as virgens consagradas, figuras típicas do movimento monástico do período. Ela será posteriormente lembrada por esse episódio, o que conduzirá à sua santificação no período medieval.

Em resumo, a obra monumental de Helena foi acrescida por Constantino, o que resultou em igrejas no Monte das Oliveiras e em Belém; Constantino acrescentou uma igreja ao Santo Sepulcro, em Jerusalém e outras, como as de Nicomedia, Antioquia, Membreia, Heliópolis, Constantinopla (especialmente aos Santos Apóstolos), dotadas de decoração riquíssima. Assim, o complexo monumental foi destino de visitação para inúmeros devotos, ou mesmo curiosos sobre esses lugares.

Após a viagem de Helena para as províncias orientais, os deslocamentos para essa localidade aumentaram. Possivelmente, ela não foi a primeira mulher a viajar para as províncias orientais do Império no século IV. É certo que foi a primeira imperatriz a fazêlo, mas não a única (LENSKI, 2004). Digamos que, nesse momento, um caminho se abriu com várias possibilidades e razões para viajar, e o antigo dito popular de que "todas as estradas levam a Roma" tomou, de fato, uma dimensão original.

\section{Egéria: o diário de viagem}

Muito instigante é o relato de Egéria. ${ }^{9}$ Redigido em primeira pessoa, seu texto exala a paisagem e o imaginário de uma viagem para a Terra Santa. ${ }^{10}$ É perceptível a necessidade de descrever a experiência estimulante de cruzar aquelas terras sagradas. Para ela, mais que uma imersão na sua espiritualidade, é também uma clara "alteridade espacial", o encontro estimulante com "outros" indivíduos e sociedades santos.

Trata-se de uma narrativa que não apenas reflete o fascínio pelo local, mas também o deslumbramento que incrementou inúmeras viagens. É uma descrição dirigida às suas "irmãs" (dominae venerabiles sorores) sobre a excursão que partiu da extrema parte ocidental do Império Romano e se dirigiu à Palestina e ao Egito, bem como aos ofícios religiosos, aos quais ela assistira em Jerusalém. Sem dúvida, se o objetivo foi escrever um

\footnotetext{
${ }^{9} \mathrm{O}$ texto tem sido também denominado Peregrinatio Aetheriae (Peregrinação de Etéria), Itinerarium Egeriae (Itinerário de Egéria).

${ }^{10}$ Este tópico deve muito à análise anterior em Siqueira (2018, p. 316-331).
} 
itinerário, ou mesmo as memórias do caminho de peregrinação, a composição induz o leitor a saborear um diário de viagem, registrando não apenas a experiência, mas também compartilhando com outras pessoas e oferecendo dados interessantes, informações úteis para uma viagem posterior. O roteiro do plano da excursão é apresentado por ela: "[...] eram-nos mostrados seguindo as Escrituras" (Egeria, Itinerarium, 1, 1). Ela foge de uma simples descrição que, como vimos, é abundante no Itinerarium Burdigalensis. Procura descrever as suas impressões pessoais em relação aos lugares visitados, cria imagens agradáveis e tenta, em alguns momentos, registrar as emoções. A autora não deixa de eventualmente considerar os usos e costumes das pessoas locais, etc.

A narrativa evidencia que a viagem é fruto de um desejo acumulado por meio da leitura bíblica. A organização do roteiro e a própria construção textual registram as experiências. Estas estão cuidadosamente subdivididas em duas partes distintas. A primeira ocupa-se do diversificado espaço geográfico. Por ser uma longa extensão com diferentes territórios, essa parte foi organizada em quatro subitens: o primeiro registra a peregrinação ao monte Sinai e a volta para Jerusalém pelas estradas da terra de Jessen; o segundo narra a visita ao monte Nebo; em seguida, Egéria descreve a viagem para a Indumeia, na terra de Jó; por fim, ela lembra a sua passagem pela Mesopotâmia e o retorno a Constantinopla, que foi feito através de Tarso, Selêucia e Calcedônia.

Dos inúmeros lugares visitados, é interessante a visita a dois monumentos dedicados a duas mulheres santificadas: Tecla e Eufêmia. A primeira venerada tem o seu santuário na Selêucia; é a santa Tecla. "E como dali a Santa Tecla, o lugar que está mais longe da cidade, numa colina, mas plana, havia talvez mil e quinhentos passos da cidade, preferi, pois, prosseguir até ali, para fazer aí a paragem que devia fazer" (Eg., It., 23,2). O santuário de Santa Tecla era um local bastante visitado por peregrinos e peregrinas. ${ }^{11}$ Não satisfeita em descrever a viagem, a peregrina acrescenta detalhes para seu público leitor: "ali cheguei, em nome de Deus, foi feita uma oração no santuário, e também lidos todos os Actos de Santa Tecla" (Eg., It., 23, 5).12 Na sequência do passeio, há outro santuário famoso acrescido ao roteiro: o de santa Eufêmia. "Cheguei à Calcedônia onde, devido ao famosíssimo santuário de Santa Eufêmia que conheço já desde há muito e que ali se encontra, descansei nesse lugar" (Eg., It., 23, 7). Constantinopla marca o final da primeira parte, ela se despede e promete que se por acaso ela cumprir outra viagem assim fará o

\footnotetext{
11 Teodoreto de Ciro (Historia religiosa, 29, 7) informa que Marana e Cira visitaram o local, imbuídas pelo desejo de contemplar os lugares santificados.

${ }^{12}$ Este texto é parte dos Atos de Paulo. Restam fragmentos em grego, chamados "Atos de Paulo e Tecla". Cf. Moreschini e Morelli (2014, p. 226).
} 
registro, "[...] se Deus se dignar conceder-mo; ou pelo menos, se um outro projecto me vier ao espírito, informarvos-ei por escrito" (Eg., It., 23, 10).

A segunda parte é importante também porque contém a descrição detalhada das liturgias cumpridas ao visitar todos os lugares, particularmente a descrição da Semana Santa professada nessa época em Jerusalém (Eg., It., 30-39, 5). Ela registra vivamente a movimentação de procissões entre um lugar e outro, repletas de cerimônias. Parece dar vida ao subir e descer dos montes de uma igreja para outra. Egéria chegou em Jerusalém em 383, na cidade considerada o lugar da ressurreição, da morte e da paixão de Cristo, onde está o Calvário. A partir deste surgiu um complexo monumental formado por três edifícios, nos quais ocorriam os rituais de todos os dias e as grandes liturgias do domingo e das festas que ela descreve vivamente. Também o Monte das Oliveiras (Eleona, em grego) é outro local mencionado repetidas vezes quando da descrição dos rituais. A liturgia é descrita por estações, em procissões que foram palco da paixão de Cristo.

Tantas questões podem suscitar a reflexão sobre as viagens e os seus motivos. Parece que a viajante quis não apenas descrever a sua viagem no estilo itinerário. A referência aos textos bíblicos evidencia que há uma preocupação em divulgar e incentivar também o fervor religioso e a perfeição cristã. A descrição da liturgia de Jerusalém, tão pormenorizada das cerimônias por ela presenciadas, ilustra a imagem de um ambiente santo, permeado por uma esfera mística de fascinação de certas cerimônias, diante das quais o povo, segundo ela, não pode deixar de reter as lágrimas: "[...] uma vez lido este passo, produzem-se tais gritos e gemidos de todo o povo, que ninguém poderia não se deixar comover até às lágrimas naquela hora" (Eg., It., 34). Também aqui está explícito o objetivo de despertar, no público leitor, tanto o fervor quanto o zelo pelos atos sagrados, a exemplo daquilo que viria pessoalmente acontecer e assistir.

Fica patente que há uma árdua defesa da fé. Ademais, há várias evidências de que muito mais do que uma viagem de cunho religioso para conhecer os lugares, homens e mulheres santos, Egéria viveu a plenitude de um desejo íntimo que queria ver realizado. A gratidão está sempre presente em suas palavras: "[...] pela minha parte, também não sou capaz de agradecer o suficiente a todos aqueles santos, que se dignavam receber a minha humilde pessoa [...]" (Eg., It., 5, 12). A realização da sua vontade profunda fez com que ela pouco se importasse com as inúmeras dificuldades do trajeto íngreme e, às vezes, perigoso: "[...] a verdade é que esforço não se sentia, por aquela parte; de fato, não se sentia esforço, porque o desejo que eu tinha via-o realizar-se, por vontade de Deus $[. . .]^{\prime \prime}(E g .$, It., 3, 1). Parece que ela está sempre pronta para se sacrificar em nome do seu desejo maior de estar naquele local e viver aquela experiência. A viagem, para ela, nada mais é do que simplesmente a testemunha da sua devoção, e da oportunidade ímpar 
de conhecer e ter um contato físico e tangível com os vestígios materiais de sua fé. A densidade dessa experiência ultrapassa a ordem narrativa de um diário de viagem; ela permite sentir também uma ação de meditação e internalização religiosa que tem um lado prático de transmitir um conhecimento por meio de uma identificação espacial.

\section{Paula: a recriação da viagem}

O repertório sobre viagens é muito antigo e cada época histórica tem o seu próprio acervo de viajantes, os quais trazem inúmeras informações sobre as formas de viajar, bem como os contextos espaciais de referência. Nosso tema aqui relaciona-se com a divulgação de um percurso educativo para os leitores da Bíblia e as pessoas convertidas ao credo cristão. Parece que o público leitor de Jerônimo recebeu informações capazes de contribuir para a formação não apenas teológica e filosófica, mas também espacial que une o aspecto geográfico ao devocional. A doutrinação cristã no vasto território romano teve de utilizar, com muita maestria, argumentos para criar imagens e representações tão ricas e instigantes quanto o tradicional mitológico e fantástico já registrado no imaginário do mundo antigo com Homero.

Assim é o relato de Jerônimo que recria a viagem de Paula. Ela de fato viajou, mas a narrativa sobre o deslocamento é fruto da imaginação de Jerônimo, que utiliza a história de uma viagem para criar uma alegoria religiosa, para fins de doutrinação e como forma de despertar o fervor e a fé por meio de uma história de viagem, para um mundo distante da grande e nobre Roma.

Sabemos como Paula viajou de Roma para vários lugares da Palestina e do Egito até chegar à Terra Santa porque Jerônimo, após a morte dela, resolveu escrever um epitáfio para homenageá-la e consolar a filha ainda triste com a ausência materna. O que seria um breve elogio fúnebre termina por se tornar praticamente uma biografia da nobre romana, na qual há um pequeno espaço, do capítulo 6 ao 14, para contar sobre a viagem de Paula em companhia da filha Eustáquia e sobre o próprio Jerônimo. Este declara que "[...] não me proponho a escrever o seu diário de viagem -, mencionarei somente os lugares recomendados nos livros sagrados" (Hieronymi, Epitaphium Sanctae Paulae, 8, 1).

É possível, assim, que a recordação da ida sem retorno para a Terra Santa tenha mais o propósito de alimentar o imaginário da órfã e do público leitor com as imagens da viagem, do que relatar a experiência em si. O início da viagem é o ano de 386 . O tom de Jerônimo é retórico e segue os padrões de escrita de sua época. Segundo ele, a inspiração da viagem veio após o encontro com alguns bispos do Oriente que vieram a Roma para participar de um sínodo. Daí, Paula decidiu conhecer o Egito, a terra que abriga os 
famosos monges ascetas, além de nutrir o desejo de se afastar da cidade e viver em plena solidão, sem seguidores, no deserto, como os monges Antônio e Paulo: “E, enfim, quando terminou o inverno, quando o mar se abriu para os barcos e os bispos retornavam para as suas igrejas, ela mesma com votos e com o desejo navegava juntamente com eles" (Hie., Ep. Sct Paulae, 6, 2). Segue a descrição da despedida da família no momento de embarque: irmão, cunhado e parentes, o filho que suplicava e a filha que chorava, um retrato pintado com as cores dramáticas dos artifícios da oratória capazes de descrever o movimento das velas do barco dançando em um vento promissor. Mesmo com a imensa dor da despedida, a renúncia da sua família, da sua cidade e do seu mundo em contraste com a esperança vindoura de um amor maior. É uma viagem sem volta, em um barco que surfa nas ondas e rasga o mar. Na proa, ela, junto aos outros passageiros que, inertes, olhavam para as margens no relance da última vista antes da separação, "desviava os olhos para não ver aqueles que não podia olhar sem tormento. Nenhuma - confesso amou a tal ponto os filhos que concedeu todas as suas posses" (Hie., Ep. Sct. Paulae, 6, 5).

Assim começa a descrição de uma viagem cujo itinerário esquadrinha uma cartografia das Sagradas Escrituras. O trajeto se inspira, sobretudo, no Antigo Testamento, evocando os seus personagens e figuras sagradas com as suas estórias e os desafios impostos para provar a fé. O Novo Testamento é mencionado principalmente quando se trata da visita a Jerusalém e Belém. Quanto aos sentimentos da viajante, há apenas algumas referências: "[...] como se tivesse asas, Paula desejava avistar Jerusalém e os lugares sagrados. Os ventos pareciam preguiçosos, a velocidade lenta" (Hie., Ep. Sct. Paulae, 7, 1). Segundo Jerônimo, Paula fez generosas doações aos mosteiros visitados, utilizou variados meios de transportes, hospedou-se em "[...] cela humilde; e percorreu todos os lugares com tanto ardor e paixão, que se não tivesse que se apressar para os outros, não poderia se separar do primeiro" (Hie., Ep. Sct. Paulae, 9, 1). Em cada local mencionado, uma passagem bíblica é evocada e, assim, os lugares são ilustrados; os túmulos, as grutas, os inúmeros lugares da Terra Santa são visitados. Diferentemente do Itinerarium Burdigalense e do Diário de Viagem de Egéria, Paula visitou Nazaré. Lemos que ela "[...] rapidamente passou por Nazaré, nutriz do Senhor [...]" (Hie., Ep. Sct. Paulae, 13, 5). O itinerário encerra-se com a apresentação da viagem ao Egito, da visita às inúmeras comunidades monásticas daquela época, uma verdadeira propaganda da vida eremítica, e conclui: "Até aqui está descrito o seu itinerário, que Paula percorreu em companhia de muitas virgens e da filha" (Hie., Ep. Sct. Paulae, 14, 4).

Infelizmente, não temos o prazer de saber da própria Paula as suas impressões dos lugares por onde passou, a percepção do movimento, a emoção do conhecimento geográfico, a experiência concreta e elusiva de viagem. Seria seguramente diferente a 
justificativa da decisão de permanecer em Belém. De qualquer maneira, ela gastou boa parte do seu tempo e dinheiro na excursão até a parada final. O que resta é a memória de uma mulher mortificada pelos jejuns e inundada por lágrimas ao beijar a pedra do Santo Sepulcro, ao ver a manjedoura do Menino Jesus. As emoções estão sempre conduzidas para um ambiente místico, permeadas pelo uso retórico intenso.

\section{Melânia Maior: a excentricidade do retorno}

A última viajante de Melânia foi argumento de diferentes autores (SIQUEIRA, 2017, p. 135-154). Uma mulher muito famosa, a sua vida foi narrada por Evágrio Pôntico, Paládio e Paulino de Nola (seu primo). Ela deixou Roma e viajou até chegar a Jerusalém, onde fundou, no Monte das Oliveiras, um mosteiro. Aí, residiu por um longo período, de 374 a 399. Essa estada prolongada, segundo Peter Brown (2014), assinala uma reviravolta, visto que anteriormente os aristocratas iam e vinham da Terra Santa apenas como simples peregrinos e peregrinas.

Mais interessante do que os diferentes discursos sobre as ações de Melânia na Terra Santa são os relatos a respeito de seu retorno. No decorrer da permanência em Jerusalém, ela viveu em isolamento, cumprindo ações de caridade junto aos inúmeros mosteiros e ajudando cristãos presos e perseguidos. Após longos anos, ela volta e eis que uma multidão de amigos e parentes vai para Nápoles recebê-la com muita pompa. Sabe-se do episódio por meio de Paulino de Nola, ${ }^{13}$ que descreve retoricamente seu itinerário desde a partida para a longa viagem. Segundo o relato, ela, com alegria, se libertou dos vínculos do amor humano e zarpou em meio aos prantos de familiares, amigos e clientes, enfrentando corajosamente os perigos do mar. Após certo tempo, voltou, atravessou o mesmo mar, desembarcou em Nápoles, onde "[...] foi acolhida pelos filhos e os netos, que foram encontrá-la, mas ela rapidamente se apressou a vir para Nola, na nossa morada, pobre mas hospitaleira, onde chegou cercada e protegida do cortejo soberbo dos seus parentes e amigos riquíssimos" (Paulino de Nola, Epistulae, 29, 12). No trajeto de aproximadamente 32 quilômetros entre o porto e o mosteiro na cidade de Nola, a comitiva em cortejo acompanhou Melânia:

Ela montada em um cavalinho magro e mais desprezível do que qualquer asnozinho; seguiam-na senadores com toda a pompa desse mundo, dos quais podiam cercar-se aqueles honrados e ricos senhores, sobre carruagens oscilantes, com cavalos adornados de fáleras, carros dourados e numerosos cocheiros, onde

${ }^{13}$ A carta de número 29, escrita provavelmente na primavera do ano 400, é uma biografia de Melânia Maior, elaborada conforme o modelo da Vita Martini, de Sulpício Severo. 
a Ápia gemeu e brilhou; mas a beleza da humildade cristã que iluminava Melânia superava em esplendor o fausto da vaidade. Os ricos admiravam esta santa assim pobre, enquanto eles zombavam da nossa pobreza (Paul. Nol., Ep., 29, 12)

O discurso da volta triunfal utiliza como recurso retórico a comparação entre a enorme riqueza da comitiva e a humildade de Melânia. A vaidade e a humildade são contrapostas ao luxo e o excesso de exibição da riqueza e da tradição familiar. Então, a longa viagem de Melânia é aqui um florilégio retórico que disfarça inteligentemente uma sociedade ambígua que equilibra o imenso paradoxo da riqueza e da pobreza. Mesmo os mais ardorosos defensores da pobreza e da vida monástica usaram e abusaram da riqueza e dos bens de viúvas, como Melânia e Paula, em prol de suas ideias religiosas.

Tanto Melânia quanto Paulino, muito ricos, pertenciam a uma geração não familiarizada com renúncias. Mesmo com a viagem, ela formalmente nunca desistiu de sua riqueza, tampouco desapareceu de repente de Roma. A viagem à Palestina não foi apressada; ela esperou o filho endossar a toga senatorial e só depois partiu navegando pelo Mediterrâneo. Ademais, não fez a excursão como simplesmente uma peregrina, mas se colocou como benfeitora de uma facção eclesiástica e, na viagem, levou fundos substanciais para apoiar a causa nicena. Em vez de ir diretamente para Jerusalém, desembarcou em Alexandria com um navio carregado de ouro e prata para ajudar as pobres povoações monásticas dos arredores de Alexandria, salvando-as das pressões do governo ariano hostil. Quando os principais monges da Nítria se exilaram na Palestina, Melânia assistiuos e defendeu-os perante o governador, lançou mão dos seus antecedentes romanos que lhe conferiam prestígio incontestável. Assim, ela proveu o sustento de pelo menos três mil monges egípcios no exílio e contribuiu para que a balança favorecesse o partido antiariano nos mosteiros e eremitérios do Egito setentrional (BROWN, 2014, p. 362).

A viagem de Melânia durou mais de vinte anos. A justificativa para o retorno, segundo ela, foi para proteger Rufino, seu tutor espiritual que estava envolvido na controvérsia origenista. É possível que a volta foi para mobilizar a renda de suas propriedades e arrecadar fundos adicionais, promovendo a vida ascética entre seus familiares, muitos dos quais eram amigos e parentes. Infelizmente, não há como saber o que Melânia pensou a respeito de suas viagens. Sabe-se apenas que ela deu uma guinada em sua vida quando zarpou em viagem e que incorporou, em sua história, também a trajetória do seu mestre espiritual.

\section{Considerações finais}

Até aqui foi possível refletir sobre Helena, Egéria, Paula e Melânia e as suas viagens. Cada qual com a sua motivação pessoal enfrentou o trajeto com os seus perigos e tentações. 
Essas viagens podem ter sido, para cada uma das viajantes, um modo de buscar salvação do seu próprio destino traçado pela tradição. A viagem é uma aspiração interior, um reflexo da vida e de suas fases. Entretanto, concretamente fazer as malas e seguir o trajeto requer a viabilidade do deslocamento. Pudemos aqui apreciar a viagem de Helena. Ainda que a sua real motivação seja um enigma, a sua presença consolidou uma estabilidade para viajar para as províncias do Oriente. Diante dos vastos domínios romanos no século IV, um pequeno local, a Palestina, passou a representar uma dimensão espiritual muito além da sua importância territorial. Uma viagem que favoreceu uma política de monumentalização cristã com a construção de igrejas, postos de hospedagem para acolher peregrinos, mosteiros nos arredores, etc. Os peregrinos e as peregrinas ansiavam experimentar aqueles locais, a terra que foi atravessada pelo Messias e os seus apóstolos.

O Itinerarium Burdigalense forneceu um traçado de uma rota e informações sobre a infraestrutura da viagem a partir de Bordéus. Ora, o mapa usou a Bíblia como um guia de viagem, com as preciosas informações sobre o que visitar nos lugares mais sagrados, que foram gradativamente sendo preenchidos com templos, igrejas e monumentos em celebração ao nascimento, crucificação e morte de Jesus. Então, Egéria segue em parte esse itinerário, mas cria o seu com muita originalidade e expressa com naturalidade o seu desejo de ali estar, ver e sentir aquela atmosfera mística, suporte da sua fé. O diário de viagem de Egéria parte da Espanha e constrói não só um traçado geográfico e topográfico, mas registra as cerimônias que cada local celebrava. Algumas vezes a narrativa cotidiana parece enfadonha, mas ela procura trazer a possibilidade de aproximação daquela paisagem exuberante e não completamente isenta. Egéria proporciona um delicioso sabor narrativo em suas memórias de viagem, incita suas amigas e realiza um ardente desejo de conhecer lugares onde milagres ocorreram, onde os verbos ver e presenciar um lugar se harmonizam em um sentimento religioso comum.

Quanto a Paula, a recriação de um itinerário ilustra muito mais um propósito proselitista e o uso de tão ilustre figura para reforçar debates intensos entre vários mestres cristãos do período, sobretudo a defesa ardorosa do movimento monástico por Jerônimo. O Epitaphium Sanctae Paulae usa a viagem para introduzir a nova vida escolhida, então ela partiu em companhia dos monges Paulino de Antioquia e Epifânio da Salamina em direção à Terra Santa para conhecer todos os lugares sagrados contidos na Bíblia. Depois de haver visitado os monges do deserto da Nítria, estabeleceu-se em Belém, onde fundou uma hospedaria para peregrinos, um mosteiro masculino e um feminino, onde viveu até sua morte em 404.

Melânia é apresentada pela sua volta de uma longa viagem, com excentricidade por seu primo e biógrafo que usa o retorno para descrever a riqueza da família em 
contraposição à humildade que ela aprendeu no decorrer daqueles anos vividos distante do luxo da aristocracia romana. Então, na perspectiva de Paulino, foi uma missão de vida que provocou uma mudança radical de perspectiva na vida daquela mulher.

Não há como deixar de mencionar, contudo, que, no caso de Helena, Paula e Melânia suas viagens foram utilizadas como argumentos persuasivos para atender aos propósitos dos autores em suas obras, em especial ao movimento monástico. Cada qual à sua maneira, eles não economizaram em argumentos e belas palavras como recursos estilísticos visando a amenizar contradições, disputas de poder e rivalidades teológicas de um mundo complexo e em constante transformação. Isso não significa que elas não tiveram vontade própria e foram apenas manipuladas por eles. É preciso salientar que essas mulheres, ao darem um novo rumo a suas vidas, incorporaram em suas histórias as trajetórias de seus mestres espirituais, o que possibilitou o registro de suas memórias para a posteridade. Se, por um lado, apoiaram as causas dos seus biógrafos, por outro, se preocuparam também em idealizar o feminino a partir da convivência com elas, e não apenas criaram estereótipos, mas concretizaram uma história de mão única, incompleta.

O que sabemos dessas viajantes são representações reduzidas e simplificadas. É fundamental problematizar o ponto de vista de quem registra a memória do outro, no nosso caso, de uma mulher. É necessário seguir os passos de Chimamanda Adichie (2019) e perceber que o poder não é apenas a possibilidade de narrar a história de uma outra pessoa, mas fazê-la uma história definitiva daquela pessoa. As memórias de Helena, Paula e Melânia estão estereotipadas, portanto, incompletas, e dificilmente saberemos o que elas esperaram das suas viagens e das inúmeras mudanças que promoveram.

\section{Referências}

\section{Documentação textual}

BÍBLIA DE JERUSALÉM. Tradução de Ivo Storniolo e José Bortolini. São Paulo: Paulus, 2002. EGERIA. Diario di viaggio. Introduzione e note di Elena Giannarelli. Milano: Paoline, 2010. EGÉRIA. Viagem do Ocidente à Terra Santa, no séc. IV. Edição de Alexandra B. Mariano e Aires A. Nascimento. Lisboa: Colibri, 1998.

EUSEBIO DI CESAREA. Vita di Costantino. Traduzione di Laura Franco. Milano: BUR-Rizzoli, 2009.

GEYER, P. (ed.). Itinerarium Burdigalense. In: Itineraria Hierosolymitana: saeculi IIIIVIII. Pragae, Vindobonae et Lipsiae: Academia Litterarum Caesareae Vindobonensis, 1898. v. XXXVIIII. 
HIERONYMI. Epitaphium Sanctae Paulae. Traduzione di Luca Canali. Trebaseleghe: Fondazione Lorenzo Valla, 2007.

ITINERARIUM BURDIGALENSE UEL HIEROSOLYMITANUM. Recensire di Gustavo Althoff. Scientia Traductionis, n. 15, p. 274-379, 2014.

PAULINO DI NOLA. Le lettere. Traduzione di Giovanni Santaniello. Nápoles: LER, 1992.

RUFINO. Storia della Chiesa. Traduzione di Lorenzo Dattrino. Roma: Cittá Nuova, 1997.

TEODORETO DE CIRO. Storia ecclesiastica. Roma: Cittá Nuova, 2000.

\section{Obras de apoio}

ADICHIE, C. N. O perigo de uma história única. São Paulo: Companhia das Letras, 2019.

BROWN, P. Per la cruna di un ago: la ricchezza, la caduta di Roma e lo sviluppo del cristianesimo, 350-550 d.C. Torino: Einaudi, 2014.

CERTEAU, M. A invenção do cotidiano. Petrópolis: Vozes, 2009.

CONSOLINO, F. E. E., la locandiera. In: FRASCHETTI, A. (org.) Roma al femminile. Roma: Laterza, 1994, p. 187-212.

CONSOLINO, F. E. E. De stercore ad regnum. In: ENCICLOPEDIA COSTANTINIANA SULLA FIGURA E L'IMMAGINE DELL'IMPERATORE DEL COSIDDETTO EDITTO DI MILANO 313-2013. COSTANTINO I. Roma: Istituto della Enciclopedia Italiana Treccani, 2013, p. $117-131.1 \mathrm{v}$.

DRIJVERS, J. W. Helena Augusta, the cross and the myth: some new reflections. In: BRANDES, W. (ed.), Millennium 8: yearbook on the culture and history of the first millennium CE. Berlin: De Gruyter, 2011, p. 125-174.

DRIJVERS, J. W. Helena Augusta: the mother of Constantine the Great and the legend of her finding of the true cross. Leiden: Brill, 1992.

ELSENER, J. The 'Itinerarium Burdigalense': politics and salvation in the geography of Constantine's Empire. The Journal of Roman Studies, v. 90, p. 181-195, 2000.

GIROTTI, B. Paola omnium romae matronarum exemplum. Bologna: BradDypUS Editore, 2014.

HARTOG, F. Memória de Ulisses: narrativas sobre a fronteira na Grécia antiga. Belo Horizonte: Editora da UFMG, 2004.

HUNT, E. D. Holy land pilgrimage in the Later Roman Empire AD 312-460. Oxford: Clarendon Press, 1984.

LENSKI, N. Empresses in the Holy Land: the creation of a Christian utopia in Late Antique Palestine. In: ELLIS, L.; KIDNER, F. L. (ed.). Travel, communication and geography in Late Antiquity: sacred and profane. Alsershot: Ashgate, 2004, p. 113-124. 
LEYERLE, B. Landscape as cartography in Early Christian pilgrimage narratives. Journal of the American Academy of Religion, v. 64, n. 1, p. 119-143, 1996.

MORESCHINI, C., NORELLI, E. História da literatura cristã antiga: grega e latina. De Paulo à Era Constantiniana. São Paulo: Loyola, 2014.

SANTI, C. Aspetti degli itinerari religiosi nel mondo classico. In: AAVV. I pellegrinaggi nell'età tardoantica e Medievale: Atti del Convegno Ferentino 6-8 Dicembre 1999. Roma: Tipografia Neri Claudio, 2005, p. 30-56.

SERRANO, S. Mulheres viajantes. Lisboa: Tintas da China, 2014.

SESSA, K. Daily life in Late Antiquity. Nova York: Cambridge University Press, 2018.

SIQUEIRA, S. M. A. Helena, Constantina e Gala Placídia: mausoléus e redefinição dos espaços sagrados na cidade antiga (séc. IV-V) d.C. In: SILVA, G. V.; SILVA, É. C. M.; LIMA NETO, B. M. (org.) Espaços do sagrado na cidade antiga. Vitória: GM, 2017, p. 314-333.

SIQUEIRA, S. M. A. Melânia: de dǒminna a serva de Cristo. Representações de mulheres aristocráticas no Cristianismo (séc. IV-V d.C.). In: ZIERER, A.; VIEIRA, A. L. B. (ed.). História antiga e medieval: conflitos sociais, guerras e relações de gênero representações e violência. São Luís: Eduema, 2017, p. 135-154.

SIQUEIRA, S. M. A. Representações espaciais da Terra Santa no "diário de viagem" de Egéria: o olhar de uma peregrina cristã no século IV. In: SILVA, G. V.; SILVA, É. C. M.; LIMA NETO, B. M. (org.) Usos do espaço no mundo antigo. Vitória: GM, 2018, p. 316-331. 